\title{
Perceptions of Grief Education in Accredited Counseling Programs: Recommendations for Counselor Education
}

\author{
Jane E. Hill \\ Lamar University \\ Richard J. Cicchetti \\ Walden University \\ Shelley A. Jackson \\ Walden University \\ G. Mihalyi Szirony \\ Walden University
}

As grief can be considered a critical life event, unresolved grief can interfere with quality of life, affecting lifestyle, behavior, emotional strength, and cognitive function. Unresolved grief can even result in suicidal ideation. Counselors can and often do work with grief issues in clients and can promote positive outcomes for grieving clients by addressing personal loss and helping clients process grief related issues. This study was based on an analysis of students within counseling programs accredited by the Council for Accreditation of Counseling and Related Educational Programs. Self-perception of competency in counseling clients who are having grief-related issues from loss was assessed using the Grief Counseling Competency Scale. By analyzing results of the Grief Counseling Competency Scale, participants showed a need for further training in grief counseling skills and theory. Results and implications of the quantitative analysis as well as suggestions for further study are discussed.

Keywords: grief, grief and loss, counseling, competency, counselor education, rehabilitation, core, CACREP, military, veterans

\section{Introduction}

Anyone can experience some form of loss during a lifetime. According to Breen and O'Conner (2011), a person can experience loss due to divorce, separation, breakup, or estrangement, or a host of other reasons (Cicchetti, McArthur, Szirony, \& Blum, 2016). Individuals can experience loss of capacity, loss of job, or loss caused by natural, human-induced disasters, or a hybrid version of such (Rozalski, Holland, \& Neimeyer, 2017; Worden, 2018). The demand for grief counseling in the United States is expected to be on the rise in the near future.

According to the U.S. Census Bureau (2017), the current population of those 65 and older, as of 2015, was 47.8 million, accounting for $14.9 \%$ of the total population. By 2060, the estimated number of people 65 and older will be 98.2 million, accounting for $24 \%$ of the population. Nearly one in four individuals is expected to be over the age of 65 . Due to an aging population, an increase in the need for grief counseling is likely to rise in an effort to assist with presenting problems related to 
disability, loss of a loved one, or grieving the loss of quality of life that one has previously experienced (Wood, 2016). More importantly, each unique individual experiences and processes loss differently, and not all will seek or have access to mental health services (Thirsk \& Moules, 2012).

At some point, if one lives long enough, one will experience loss of some type, often severe enough to affect quality of life. According to the National Institute of Mental Health (2018), one in five adults in the United States will experience a mental health-related disorder, and about $4.2 \%$ of adults aged 18 or higher will experience a serious mental illness. Although mental health services may not always be accessible (Jones, Lebrun-Harris, Sripipatana, \& Ngo-Metzger, 2014), there was an increase in the use of mental health services in older adult populations ranging in the ages of 65 years and older. With an increase predicted in a demographic shift toward an aging population, Reynolds, Pietrzak, El-Gabalawy, Mackenzie, and Sareen (2015) substantiated evidence of increased mental health disorders in adults 65 years and older, noting what they described as relatively high rates of psychiatric disorders among older adults.

There are challenges in assuring that mental health counselors are prepared to meet the increasing demand for providing grief counseling services (Imhoff, 2015). For instance, there exists a lack of professional standards for grief training and practice in the mental health counseling field, and additionally, there is limited grief education and training within counseling programs (Doughty Horn, Crews, \& Harrawood, 2012; Ober, Granello, \& Wheaton, 2012). Furthermore, there is a need for defining competency standards in grief counseling within the counseling profession. As a result, in the present study, after gathering demographic variable information, we examined levels of perceived competency in grief education and training among master's-level counseling students. The Grief Counseling Competency Scale (GCCS) instrument was used to gather data on self-reported competency using a Likert-type scale on four levels: personal competencies, conceptual skills and knowledge, assessment skills, and treatment skills. Data were statistically analyzed using a quantitative analysis comparison. Although several theories can be used to define the grief response, a summary of the most salient theories follows.

\section{Wellness}

Working with clients experiencing grief and loss can be draining for counselors, both mentally and emotionally. Counselor wellness is essential, consisting of being mentally, physically, and emotionally stable, remaining self-aware of biases or impairments, being able to recognize stress because it can be insidious, not easily identified, and being willing to take appropriate action to promote wellbeing (Blount \& Mullen, 2015). Mindfulness has been addressed in the literature in relation to wellbeing (Stauffer \& Pehrsson, 2012). Mindfulness methods are noted as both personally and professionally beneficial for counselors as well as clients. In addition, counselors have an ethical responsibility to be prepared to work with clients, and grief and loss issues are common. Counselors have the responsibility to the profession and to the client to take the necessary steps to promote their own wellbeing and to promote the wellbeing of the clients they serve (American Counseling Association, 2014).

\section{Grief Theory}

Although modern grief process theory can be traced back to Freud, it is based in large part on attachment theory (Bowlby, 1980). Freud believed that individuals grieving loss of a loved one had to work through the loss and become emotionally detached. According to Freud, an ongoing relationship with the lost loved one could be considered to be pathological. Bowlby (1958), on the other hand, 
posited a deficit model consisting of four stages of grief, having described grief as something one might get over. The four phases that Bowlby discussed are numbing, yearning and searching for the deceased person, disorganization and despair, and a greater or lesser degree of reorganization.

Other grief theorists, including Kubler-Ross (1969), Rando (1993), and Worden (2018), rejected the deficit model in favor of accommodating for a loss that might change over time. Although various models exist, there is no one model that can be applied universally. A framework for understanding the bias individuals may face could provide insight into how to better determine a more appropriate method of grief treatment for each unique, individual client. As a result, Bowlby's attachment theory was aligned with the current study.

\section{Modern Grief Theory}

The theoretical framework used for this quantitative study was modern grief theory. Modern grief theory is based on John Bowlby's work on attachment theory (Carr \& Cortina, 2011). Bowlby (1980) posited attachment theory as a conceptual framework for understanding grief. Bowlby described attachment as a psychological connectedness between individuals, whereby a sense of security and trust can be gained through the use of empathy. When the attachment to another person ends due to significant loss, such as separation or death, the remaining individual grieves.

Given that grief is an experience that essentially all people will experience, the need for competency as grief counselors exists. Given the gap in the literature regarding master's-level counseling students' self-reported competency, training, and education in providing grief counseling (Cicchetti et al., 2016; Ober et al., 2012), the purpose of the present study, based on research gathered during one of the author's dissertations (Wood, 2016), was to examine master's-level counseling students' perceptions of preparedness for identifying and working with clients presenting with grief issues and in providing grief counseling to clients in need. The significance of the study is unique in that it addresses an important and under-researched area of the competency of master's-level counseling students in providing grief counseling (Doughty Horn et al., 2012; Ober et al., 2012). Following the study conducted by Cicchetti (2010), the purpose of the present quantitative analysis was to examine perceived competency levels of master's-level counseling students in mental health programs regarding their preparedness, education, or training received in grief theories or counseling skills in their Council for Accreditation of Counseling and Related Educational Programs (CACREP)accredited programs. Data from a more extensive quantitative study by Wood (2016) was used in this current study.

The following research questions were addressed and subsequently analyzed:

Research Question 1: How do the demographic variables (gender, age bracket, race, and ethnicity) relate to perceived grief counseling competency?

Research Question 2: Controlling for course offerings (i.e., whether or not the participant's course curriculum offered coursework in grief counseling theories and practice), what is the relationship between coursework and grief counseling competency? 


\section{Method}

\section{Participants}

Participants $(N=123)$ consisted of individuals enrolled in CACREP-accredited programs. Three hundred fifteen program directors or program designees received the survey. Out of 315 designees, 25 returned automatic email responses, 24 were forwarded to their students, and the remainder of contacted designee emails was inconclusive.

\section{Measures}

A modified version of Cicchetti's (2010) GCCS was used for the study. Internal consistency reliability for the GCCS was established by calculating a Cronbach's alpha for each section and the subscales. An alpha level calculated for the GCCS was calculated for the two sections of the survey, which included Part I: Personal Competency and Part II: Skills and Knowledge Section. The alpha level for the Personal Competency section was found to be .69, and the alpha level for the Skills and Knowledge section was .97. Alpha levels for the three subscales of the Part II: Skills and Knowledge scale follow. For the Conceptual Skills and Knowledge subscale, the alpha was .94; for the Assessment Skills subscale, the alpha level was measured at .85; and for the Treatment Skills subscale, the alpha was .93. The alpha levels for the three subscales of the GCCS suggested relatively high internal consistency. In addition, the alpha level for the overall section, Skills and Knowledge, was .97. It was deemed acceptable. In addition, according to Cicchetti (2010), a demographically diverse group of grief experts rated and provided comments on the importance of the included GCCS competency items and the efficacy of the modified Delphi procedure to determine validity. Content validity was indicated by 14 of the 15 (93.3\%) experts who agreed the included competency items in the GCCS survey adequately or completely addressed the characteristics and the competencies required for grief counseling (Cicchetti, 2010).

\section{Procedure}

Upon Institutional Review Board approval, data collection took place over a period of 40 days. A convenience sampling of CACREP-accredited master's-level mental health counseling programs was conducted. SurveyMonkey was used to design and disseminate the survey electronically. No external funding was used to support this study. Participation was strictly voluntary and participants remained anonymous throughout the study. A nonexperimental, one-shot survey comparative design was employed. The GCCS chosen and modified for this study was a redesigned version of the Death Competency Scale (Charkow, 2002; Cicchetti et al., 2016). The modified GCCS was designed to measure master's-level mental health counseling students' interpretations of their perceived related training and ability to treat clients experiencing grief or loss. The GCCS produces four continuous variables of personal competencies, conceptual skills and knowledge, assessment skills, and treatment skills. In the Wood (2016) study, information on content validity and reliability was sent out for expert evaluation. Feedback from experts in the field concluded that the modified GCCS survey was appropriate for the study.

\section{Population}

For the present study, a population of master's-level students enrolled in CACREP-accredited mental health counseling programs was chosen, differing from the Cicchetti (2010) study, which measured perceptions of master's-level rehabilitation counseling students in CORE programs. Both 
studies surveyed master's-level students who were in their internship or practicum settings and had completed all required coursework. The only noted modification in the GCCS used for this study was the removal of the word disability from eight questions in the section labeled Part II. A survey invitation provided detailed instructions to participants who were interested in participating in the study. The email invitation included a clickable next button so that those who chose to do so could begin their review of the consent form. Participants who chose to continue to the electronic survey following the consent form provided remained anonymous. Participants were able to cease participation at any time. The final sample size consisted of 153 respondents, of whom 123 answered all survey questions.

\section{Results}

\section{Research Question 1}

Descriptive statistics were computed to examine the data from the survey. Data from the survey were analyzed to answer the research question, which was adapted from Cicchetti (2010). Research Question 1 asked, "How do the demographic variables (e.g., gender, age bracket, race, and ethnicity) relate to perceived grief counseling competency?"

To answer Research Question 1, a four-way multiple analysis of variance was computed on four demographic variables_-gender, age bracket, race, and ethnicity-against the four grief competency (GCCS) subscales as outcome variables. Of the 153 master's-level CACREP counseling students who were in either their practicum or internship stages and participated in this study, 136 (89.47\%) reported being female, 16 (10.53\%) reported being male, and one participant chose not to respond. One hundred forty-two (92.81\%) identified as not of Hispanic, Latino, or Spanish origin; four (2.61\%) identified themselves as Mexican, Mexican American, or Chicano; three (1.96\%) identified themselves as Puerto Rican; and foour (2.61\%) identified as other Hispanic, Latino, or Spanish in origin (0 identified as Cuban); 126 (82.89\%) identified themselves as White; 18 (11.84\%) as Black, African American, or Negro; three (1.97\%) as American Indian or Alaska Native; one as Filipino; two (1.32\%) as other Asian; one (0.66\%) as Guamanian or Charnorro; one (0.66\%) identified as other Pacific Islander; and one participant chose not to respond.

Thirty percent of participants ranged in age from 18 to 24 , $45 \%$ were in the $25-34$ age bracket, $8 \%$ were in the $25-44$ bracket, about $12 \%$ responded in the age bracket of $45-54$, and a little over $3 \%$ responded being in the age bracket of 55 and over. Reporting on practicum or internship settings, 72 were in community mental health settings, 51 were in school settings, 2 were in a hospital setting, one was in a rehabilitation setting, four were at state agencies, two were in residential settings, and 19 indicated being in settings other than those given. Two individuals did not respond to this item.

Question 1 was investigated using a four-way multiple analysis of variance with demographic variables (gender, age bracket, race, and ethnicity) as independent variables, and the four grief competency subscales on the GCCS are the dependent variables.

The first demographic variable, gender, was examined. Ninety-three females and 12 males were examined for differences on perceived grief counseling competency on the GCCS survey. No significance for gender as a function of perceived grief counseling competency was found. Next, the demographic variable age was compared to the perceived grief counseling competencies on the GCCS survey for the 105 respondents. A main effect was found for age and perceived personal competency related to grief, $F(16,236)=2.736, p=.034$, indicating that we can reject the hypothesis that there is 
not a significant interaction effect among the demographics variable age and perceived grief counseling competency in personal competency. The multivariate $\eta^{2}=.12$ indicates $12 \%$ of multivariate variance of the dependent variable personal competency is associated with age (see Table 1). One hundred five participants' demographic variable race was compared to the perceived grief counseling competency on the GCCS survey. There was no significance found for race and perceived grief counseling competency. One hundred five participants' demographic variable ethnicity was compared to the perceived grief counseling competency on the GCCS survey. There was no significance found for ethnicity and perceived grief counseling competency. Partial support was found for Research Question 1. No significant effect was found on variables gender, race, ethnicity, or perceived grief counseling competency. However, a significant effect was found for the demographic variables age and perceived grief counseling competency.

Table 1. Relationship Between Age and Grief Counseling Competency

\begin{tabular}{llll}
\hline Dependent Variable & $F$ & $p$ & $\eta^{2}$ \\
\hline Personal competency & 2.736 & .034 & .120 \\
Assessment skills & .603 & .661 & .029 \\
Treatment skills & .682 & .607 & .033 \\
Conceptual skills and knowledge & .713 & .585 & .034 \\
\hline
\end{tabular}

\section{Research Question 2}

The second research question asked, "Controlling for course offerings (i.e., whether the participant's course curriculum offered coursework in grief counseling theories and practice), what is the relationship between coursework and grief counseling competency? This question was answered using a multiple analysis of covariance. The independent variable in Research Question 2 in this study was coursework. The four grief competency subscales on the GCCS served as the dependent variables, and the covariate was course offering. This analysis examined the relationship between course work taken and the four grief competency subscales on the GCCS survey, which included the four subscale levels of personal competencies, conceptual skills and knowledge, assessment skills, and treatment skills.

Controlling for course offerings, a main effect was found having taken course work in either grief theories or grief interventions, and competency in the grief counseling competency scales dependent variable assessment skills, treatment skills, and conceptual skills and knowledge. A main effect was found for the presence of coursework taken and perceived assessment skills related to grief counseling competency, $F(12,254)=3.134, p=.029$, indicating a significant positive relationship between coursework taken and perceived grief counseling competency in assessment skills, controlling for course offerings.

The multivariate $\eta^{2}=.087$ indicated $8.7 \%$ of multivariate variance of the dependent variable assessment skills was associated with coursework taken and grief counseling competency. A main effect was found for the presence of coursework taken and perceived treatment skills related to grief counseling competency, $F(12,254)=3.252, p=.025$, indicating a significant positive relationship between coursework taken and perceived grief counseling competency in treatment skills, controlling for course offerings. The multivariate $\eta^{2}=.090$ indicated $9.0 \%$ of multivariate variance of the dependent variable treatment skills to be associated with coursework taken and grief counseling competency. A main effect was found for the presence of coursework taken and perceived conceptual skills and knowledge related to grief counseling competency, $F(12,254)=4.986, p=.003$, also indicating a significant positive relationship between coursework taken and perceived grief 
counseling competency in conceptual skills and knowledge, controlling for course offerings. The multivariate $\eta^{2}=.131$ indicated $13.1 \%$ of multivariate variance of the dependent variable conceptual skills and knowledge could be associated with coursework taken and grief counseling competency.

\section{Discussion}

As counselors share the responsibility to take steps to promote personal wellbeing as well as promoting the wellbeing of the clients they serve, remaining aware of biases, impairments, and recognizing stress related to grief and loss are salient. According to grief theory, understanding the process of grief and possible interventions calls for added content in counseling coursework. In summary, for the first research question, there was no effect found for gender, race, and ethnicity or perceived grief counseling competency. However, significance was found for age and perceived grief counseling competency in regard to personal competency on the GCCS survey. Overall, the hypothesis for research added credence to the Cicchetti study (2010).

In summary, for the second research question, "What is the relationship between coursework and grief counseling competency?" a multiple analysis of covariance analysis found a main effect between course work taken and the four grief competency subscales on the GCCS survey. The results added support for closer examination of coursework in regard to increasing competency and training in counselors working with clients experiencing issues related to grief, in support of modern and other grief theories.

\section{Recommendations for Professional Practice}

The results from this study based on grief theory supported a need for grief education and training in grief theory and practice to be part of CACREP-accredited master's-level counseling programs. Recommended curricular enhancements may include grief and loss education, attachment theory, dual process model of grief, meaning making theory, and adaptive grieving styles in CACREPaccredited programs. Furthermore, adding a social and cultural diversity component on loss, grief, and exploration of cultural rituals for grieving would be helpful. Adding to the human growth and development section of curriculum, students could create a lifeline of losses, journal about their losses (written or via video), or tell a story about their experiences pertaining to loss and grief (Doughty Horn et al., 2013; Parikh, Janson, \& Singelton, 2012).

Grief and loss could also be included in career development courses by addressing concerns over loss of a job, loss of a career, financial security and loss of income, loss of identity, self-respect, career change and social status (Sterner, 2012). Grief and loss could also be integrated into crisis counseling courses to address a survivor's reaction to a traumatic physiological or sociophysiological event, including but not limited to a loss of limb(s), loss of function, or a major change in way of life. Students might also look through a lens of perception of loss or grief in practicum and internship courses when a client experiences a change in lifestyle. In group work, existential group techniques can be taught along with group psychotherapy for grief or curriculum-based model for grief support groups (Joyce, Ogrodniczuk, Piper, \& Sheptycki, 2010; Rosner, Lumbeck, \& Geissner, 2011).

It appears important for faculty and administrators within CACREP-accredited colleges and universities working with practicum or internship sites to ensure students will receive grief education and training when working with clients presenting with grief issues, an issue not uncommon in counseling settings. Participants surveyed in this study may not have taken a course 
in grief theory and intervention. CACREP-accredited institutions by and large do not offer courses in grief theory or grief intervention. Results of the current study supported this notion.

\section{Conclusion}

In summary, the purpose of this study was to examine master's students' perceived competency levels in grief education and training in CACREP-accredited mental health counseling programs. Results from this study coupled with grief theory suggested a need for CACREP-accredited programs to reevaluate core curriculum requirements. There appears to be a need to expand the current core curriculum requirements to include grief theory and intervention (Harrawood, Doughty, \& Wilde, 2011). Based on results of the study, participants who were introduced to grief theory and content in their master's-level programs perceived themselves to be more competent in grief theory, assessment, and intervention.

Ober, Granello, and Wheaton (2012) concluded licensed professional counselor participants who had obtained grief education or training rated themselves at higher levels of competency in comparison to licensed professional counselor participants who did not complete any grief education or training. Evinced by the results of the current study, those master's-level students in accredited programs who had coursework related to grief theories and interventions perceived themselves better equipped to work with clients who were experiencing the effects of grief from loss. Support for this premise can be concluded from the present study and suggests further analysis of the need for reevaluation of CACREP requirements to include grief education and training in core curriculum.

\section{References}

American Counseling Association. (2014). ACA code of ethics. Alexandria, VA: Author.

Blount, A. J., \& Mullen, P. R. (2015). Development of an integrative wellness model: Supervising counselors-in-training. The Professional Counselor, 5, 100-113.

Bowlby, J. (1958). The nature of the child's tie to his mother. International Journal of Psychoanalysis, 39, 350-371. Retrieved from http://www.psychology.sunysb.edu/attachment/online/nature $\% 20$ of $\% 20$ the $\% 20$ childs $\% 20$ tie $\%$ 20bowlby.pdf

Bowlby, J. (1980). Attachment and loss (Vol. 3). New York, NY: Basic Books.

Breen, L. J., \& O’Conner, M. (2011). Family and social networks after bereavement: Experiences of support, change and isolation. Journal of Family Therapy, 33, 98-120. doi:10.1111/j.14676427.2010.00495.x

Carr, E., \& Cortina, M. (2011). Heinz Kohut and John Bowlby: The men and their ideas. Psychoanalytic Inquiry, 31, 42-57. doi:10.1080/07351690.2010.512847

Charkow, W. B. (2002). Family-based death and grief-related counseling: Examining the personal and professional factors that impact counselor competence (Doctoral dissertation). Dissertation Abstracts International, 62(12-A), 4070.

Cicchetti, R. J. (2010). Graduate students' self-assessment of competency in grief education and training in core accredited rehabilitative counseling programs (Doctoral dissertation). Available from ProQuest Dissertations and Theses database. (Accession Order No. AAI3407393). 
Cicchetti, R. J., McArthur, L., Szirony, G. M., \& Blum, C. R. (2016). Perceived competency in grief counseling: Implications for counselor education. Journal of Social, Behavioral, and Health Sciences, 10, 3-17. doi:10.5590/JSBHS.2016.10.1.0

Doughty Horn, E. A., Crews, J. A., \& Harrawood, L. K. (2013). Grief and loss education: Recommendations for curricular inclusion. Counselor Education \& Supervision, 52, 70-80. doi:10.1002/j.1556-6978.2013.00029.x

Harrawood, L. K., Doughty, E. A., \& Wilde, B. (2011). Death education and attitudes of counselorsin-training toward death: An exploratory study. Counseling \& Values, 56, 83-95. doi:10.1002/j.2161-007X.2011.tb01033.x

Imhoff, B. A. (2015). An exploratory study of grief counseling training and competencies in counseling students at CACREP-accredited institutions (Doctoral dissertation). Department of Counseling and Higher Education, Ohio University.

Jones, E., Lebrun-Harris, L. A., Sripipatana, A., \& Ngo-Metzger, Q. (2014). Access to mental health services among patients at health centers and factors associated with unmet needs. Journal of Health Care for the Poor and Underserved, 25, 425-436.

Joyce, A. S., Ogrodniczuk, J. S., Piper, W. E., \& Sheptycki, A. R. (2010). Interpersonal predictors of outcome following short-term group therapy for complicated grief: A replication. Clinical Psychology and Psychotherapy, 17, 122-135. doi:10.1002/cpp.686

Kubler-Ross, E. (1969). On death and dying. New York, NY: Macmillan Publishing.

National Institute of Mental Health. (2018). Mental illness. Retrieved from https://www.nimh.nih.gov/health/statistics/mental-illness.shtml\#part_154790

Ober, A. M., Granello, D., \& Wheaton, J. E. (2012). Grief counseling: An investigation of counselors' training, experience, and competencies. Journal of Counseling \& Development, 90, 150-159. doi:10.1111/j.1556-6676.2012.00020.x

Parikh, S. B., Janson, C., \& Singleton, T. (2012). Video journaling as a method of reflective practice. Counselor Education and Supervision, 51, 33-49. doi:10.1002/j.1556-6978.2012.00003.x

Rando, T. A. (1993). Grief and mourning: Accommodating to loss. In H. Wass \& R. A. Neimeyer (Eds.), Dying: Facing the facts (pp. 211-242). Bristol, PA: Taylor \& Francis.

Reynolds, K., Pietrzak, R. H., El-Gabalawy, R., Mackenzie, C. S., \& Sareen, J. (2015). Prevalence of psychiatric disorders in U.S. older adults: Findings from a nationally representative survey. World Psychiatry, 14, 74-81.

Rosner, R., Lumbeck, G., \& Geissner, E. (2011). Effectiveness of an inpatient group therapy for comorbid complicated grief disorder. Psychotherapy Research, 21, 210-218.

Rozalski, V., Holland, J. M., \& Neimeyer, R. A. (2017). Circumstances of death and complicated grief: Indirect associations through meaning made of loss. Journal of Loss and Trauma, 22, 11-23.

Stauffer, M., \& Pehrsson, D. E. (2012). Mindfulness competencies for counselors and psychotherapists. Journal of Mental Health Counseling, 34, 227-239.

Sterner, W. R. (2012). Integrating existentialism and Super's life-span, life-space approach. The Career Development Quarterly, 60, 152-162. doi:10.1002/j.2161-0045.2012.00013.x

Thirsk, L. M., \& Moules, N. J. (2012). Considerations for grief interventions: Eras of witnessing with families. Omega: Journal of Death \& Dying, 65, 107-124. doi:10.2190/OM.65.2.b 
U.S. Census Bureau. (2017). Facts for features: Older Americans month: May 2017 [Release number CB17-FF.08]. Retrieved from https://www.census.gov/newsroom/facts-for-features/2017/cb17ff08.html

Wood, J. E. (2016). Master students' self-assessment of competencies in grief education and training in CACREP-accredited counseling programs (Doctoral dissertation). College of Counselor Education and Supervision, Walden University.

Worden, J. W. (2018). Grief counseling and grief therapy: A handbook for the mental health practitioner. New York: Springer.

The Journal of Social, Behavioral, and Health Sciences is an open-access, peer-reviewed, online interdisciplinary journal focusing on research findings that address contemporary national and international issues. Its objectives are to (a) encourage dialogue between scholars and practitioners in the social, behavioral, and health sciences that fosters the integration of research with practice; (b) promote innovative models of interdisciplinary collaboration among the social, behavioral, and health sciences that address complex social problems; and (c) inform the relationship between practice and research in the social, behavioral, and health sciences.

Walden University Publishing: http://www.publishing.waldenu.edu 